\title{
From Expected Cash Flows to Real Options
}

\author{
Thomas E. Copeland \\ CRA International, MIT
}

This article attempts to answer some of the most common questions about how to apply the theory of real options to practice. Its primary focus is on how to start with irregular expected cash flows of the underlying risky asset that do not follow any regular stochastic process and end up with a legitimate real options analysis. It is organized as follows. Section I is a simple numerical example. Section II discusses the necessary theory -- three key assumptions. Section III discusses how to estimate volatility. Section IV goes on to describe six short case examples where the solution process worked well. The paper discusses why traditional NPV methodology forces false mutually exclusive alternatives and how real options solves the problem, and illustrates how modularity of project construction can be more valuable than significant economies of scale. Section V discusses some of the areas where more research is needed to make the theory work well in practice.

\section{The Problem of Irregular Expected Cash Flows}

The majority of academic articles start with the assumption that the cash flows of the underlying risky asset follow a standard and well-specified stochastic process, but the real world is not so convenient. Suppose that the expected cash flows look like those in table 1 . When discounted at $10 \%$, the net present value of the cash flows at $t=0$ is $\$ 87.30$. Figure 1 shows the bar chart of free cash flows. Their pattern is nothing like any normal stochastic process. How do we go from these expected cash flows to real options?

The key point is to remember that decisions are not based on cash flows - they are based on shareholders' wealth. It is useful to examine how shareholder wealth grows as a project progresses in order to

(Multinational Finance Journal, 2010, vol. 14, no. 1/2, pp. 1-27)

(C) Multinational Finance Society, a nonprofit corporation. All rights reserved. DOI: $10.17578 / 14-1 / 2-1$ 
TABLE 1. Expected Free Cash Flows for a 5-Year Project

\begin{tabular}{|c|c|c|c|c|c|c|c|}
\hline $\operatorname{Yr}(\mathrm{t})$ & $\mathrm{E}(\mathrm{FCF})$ & PV@10\% & PV@Yr.0 & PV@Yr.t & PV ex-div. & $\begin{array}{l}\text { Wealth } \\
\text { Relative }\end{array}$ & Return \\
\hline 0 & $-1,500$ & 1.000 & $-1,500.00$ & 87.30 & $1,587.30$ & 87.30 & \\
\hline 1 & -100 & 0.909 & -90.90 & $1,746.53$ & $1,846.53$ & 96.03 & $10 \%$ \\
\hline 2 & 500 & 0.826 & 413.00 & $2,031.18$ & $1,531.18$ & 105.63 & $10 \%$ \\
\hline 3 & 800 & 0.751 & 600.80 & $1,684.30$ & 884.30 & 116.19 & $10 \%$ \\
\hline 4 & 700 & 0.683 & 478.10 & 972.73 & 272.73 & 127.81 & $10 \%$ \\
\hline 5 & 300 & 0.621 & $\frac{186.30}{87.30}$ & 300.00 & 0 & 140.59 & $10 \%$ \\
\hline
\end{tabular}

conceptualize the movement in the value of the project over time. Column 2 of table 1 provides the expected cash flows each year, and column 6 is the present value of the project ex dividend (if each cash flow is a surrogate for a dividend).

For example, the present value of the project in year 2 is $\$ 2,031.18$, which is the present value as of year 2 (at a $10 \%$ discount rate) of $\$ 300$ in year $5(P V=\$ 225.39), \$ 700$ in year $4(P V=\$ 578.51), \$ 800$ in year 3 $(P V=\$ 727.27)$, plus $\$ 500$ in year 2 . When the project throws off $\$ 500$ of cash flow in year 2 , its ex-dividend value falls to $\$ 1,531.18$. As a percent of the value, at the beginning of the period the $\$ 500$ dividend is $24.62 \%$. Note that the rate of return on capital with dividends reinvested is the same every year, namely $10 \%$.

Now suppose that there is an American option to expand the project (and to increase its present value) by $40 \%$ at any time for a cost of $\$ 700$. How is the investment decision made? First, it is necessary to have a few additional facts. The default-free rate of interest is $5 \%$ per year and the volatility of the value of the project that can be used in a binomial tree can be thought of as an up movement of 1.30 or a down movement of $1 / 1.3=.77$ per year. A little later the article will flesh out where the volatility estimate comes from. For now, let's be glad that it is given.

To solve the problem, start with the fact that the decision to expand the project will be based on the value of the project during its remaining life, not on the cash flow during a given year. The expected value at time $t$ is the present value of the projected cash flows from time ton, discounted back to time $t$ :

$$
P V @ t=E\left(V_{t}\right)=\sum_{i=1}^{N} \frac{E\left(F C F_{i}\right)}{(1+k)^{i-t}} \quad t=0,1, \ldots, N
$$




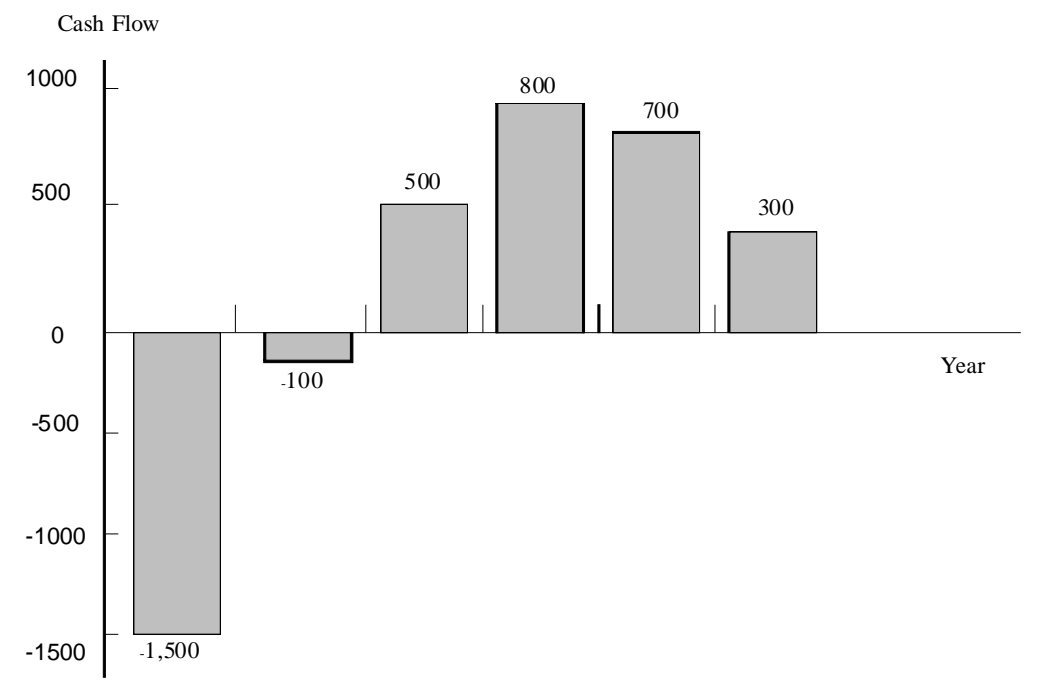

\section{FIGURE 1.- Annual Cash Flows}

Equation 1 is called a value branch. The calculation for year 2 was described just below table 1 . When all of the years are drawn on the same graph the result looks like the solid line in figure 2. It shows the present value of cash flows from year t to the end of the life of the project. Like most projects, this one starts with a low but positive value, increases in value as it seasons, then declines in value as it nears the end of its useful life. The numbers that are plotted in figure 2 can be found in column 5 of table 1 (labeled $P V @ t$ ). The wealth of shareholders, called wealth relative, is defined as the present value of shareholders' wealth at any point in time, assuming that dividends are reinvested at a rate equivalent to the cost of capital. Taking year two as an example, the wealth relative is equal to the original investment of (minus) $\$ 1,500$ brought forward for 2 years at $10 \%(-\$ 1,815)$, plus the additional $\$ 100$ investment in year 1 brought forward for 1 year at $10 \%$ $(-\$ 110)$, plus the present value of all of the expected cash flows remaining in the project, $(\$ 2,031.18)$. This sum equals $\$ 106$ which is also equal to the net present value of the project (\$87.30) brought forward two years at $10 \%$ (in table 1, column 7). Note that the expected rate of increase in shareholder's wealth (their wealth relative) is exactly 


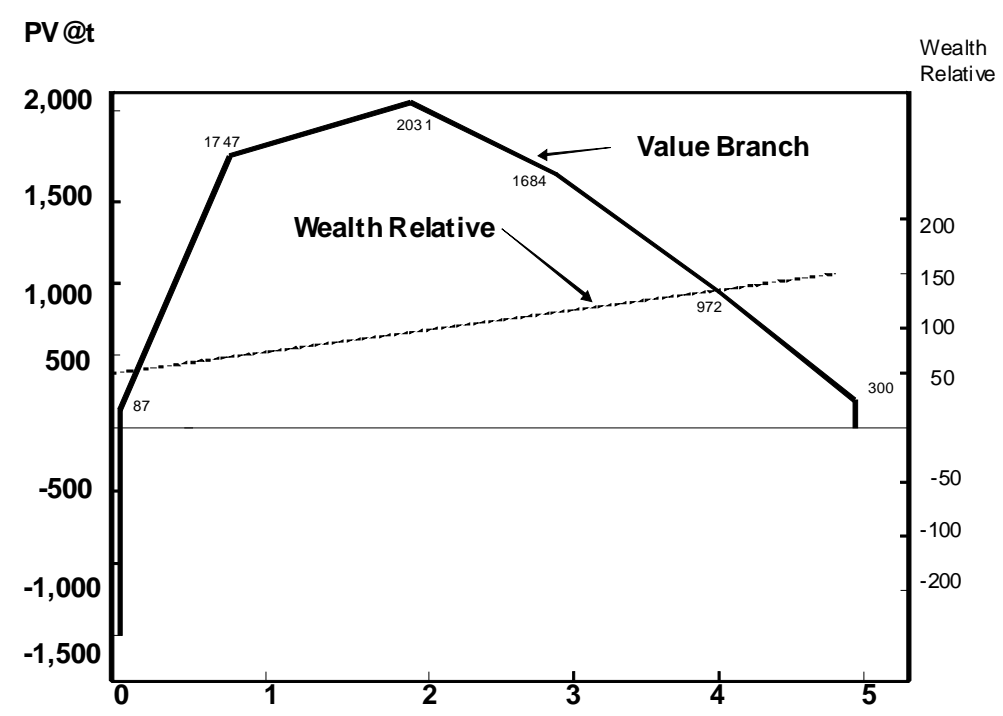

FIGURE 2.- Project Value Branch and Wealth Relative

equal to the cost of capital, namely $10 \%$. Only unexpected deviations from the pattern of expected cash flows can cause the return to be different than $10 \%$. Next, add uncertainty to the picture to obtain the value tree that is illustrated in figure 3 . Assume that value goes up by a factor of 1.3 or down by its inverse. That implies that the first year value, although expected to be $\$ 1,747$, will actually be higher at $\$ 2,270$ or lower at $\$ 1,343 .{ }^{1}$ It then moves up or down proportionately from each of these values to reflect the expected dividend payment as a proportion of the expected value. Since cash flow is negative $\$ 100$ in the first year, shareholders must invest an additional expected amount of $\$ 100$ which is $5.73 \%$ of the expected value. This moves the value up to $\$ 2,400$ or down to $\$ 1,420$ and these become the starting points for additional up or down movements. ${ }^{2}$ The assumption of proportional cash payments preserves the expected cash flow and causes the binomial tree to be recombining.

1. Note that $\$ 2,270=\$ 1,587(1.3)(1.1)$ and that $\$ 1,343=(1 / 1.3) \$ 1,587(1.1)$.

2. Note that $\$ 2,270+0.0573(\$ 2.270)=\$ 2,400$, and that $\$ 1,343+0.0573(\$ 1.343)=$ $\$ 1,420$. 


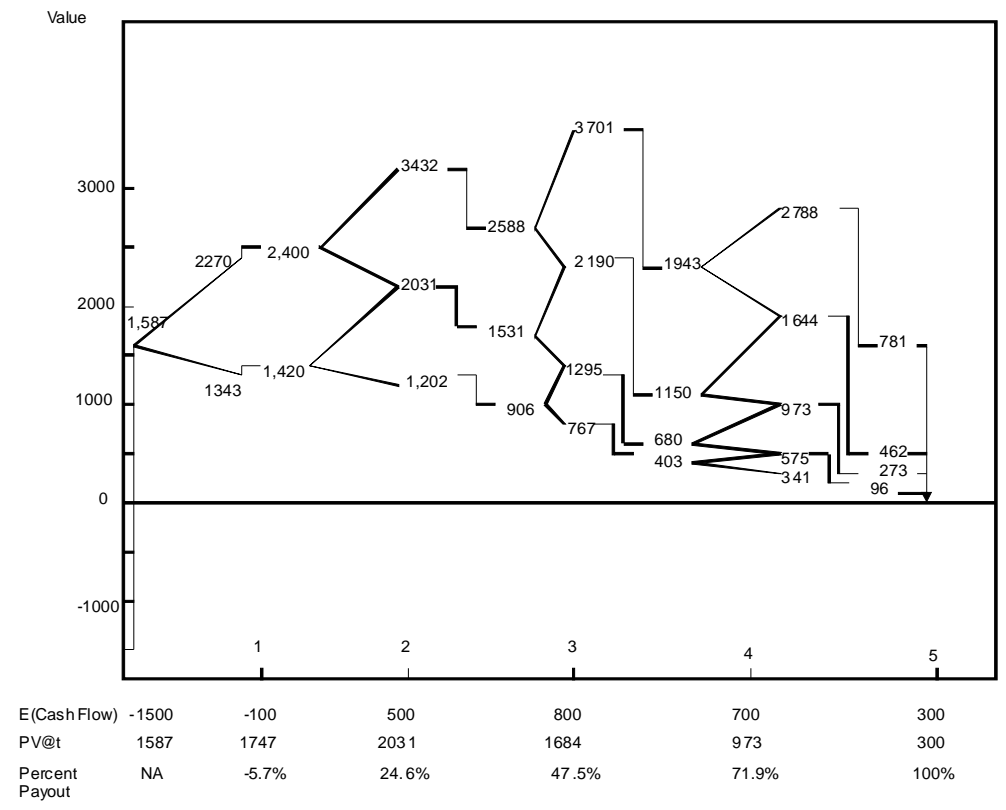

FIGURE 3.- Project Value Tree

Analysis of the option to expand begins with figure 4. Start with the payouts at the end branches. The cost of expansion is $\$ 700$ and the value enhancement is assumed to apply to the project over its remaining years. It makes no sense to expand in the last period. Even in the highest state of nature, the net payout is greater by keeping the option alive (i.e. \$781) instead of exercising it (i.e.\$393). Stated mathematically,

$$
\operatorname{MAX}[1.4(781)-700,781]=\operatorname{MAX}[343,781]=781
$$

These facts allow calculation of the objective probabilities implicit at each stage of the project. Designate " $p$ " as the probability of an up movement, and " $1-p$ " as the probability of a down movement. Then for each node of the value tree:

$$
P V_{t}=\frac{E\left(P V_{t+1}\right)}{(1+k)}=\frac{p V_{u}+(1-p) V_{d}}{(1+k)}
$$




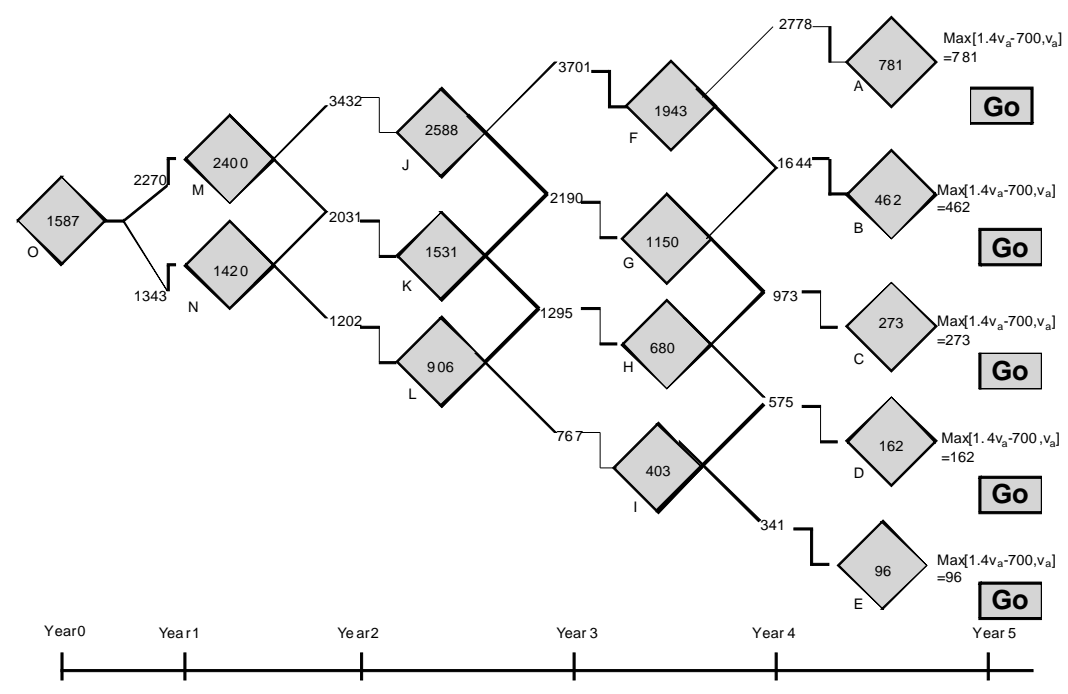

FIGURE 4.- - Value Tree with Option to Expand at End Node

$$
p=\left[P V_{t}(1+k)-V_{d}\right] /\left(V_{u}-V_{d}\right)
$$

and at the node $\mathrm{K}(t=2)$, for example,

$$
p=(1,531(1.1)-1,295) /(2,190-1,295)=0.435
$$

Check this result by calculating the expected "dividend" payout at the end of the second year as ${ }^{3}$

$$
\begin{gathered}
E(C F)=p^{2} C F_{u u}+2 p(1-p) C F_{u d}+(1-p)^{2} C F_{d d} \\
=0.435^{2}(844)+2(0.435)(0.565) 500+(1-0.435)^{2} 296 \\
=159.7+245.8+94.5=500
\end{gathered}
$$

3. The payout in the up state is $24.6 \%$ of $\$ 3,432$, which equals $\$ 844$. 


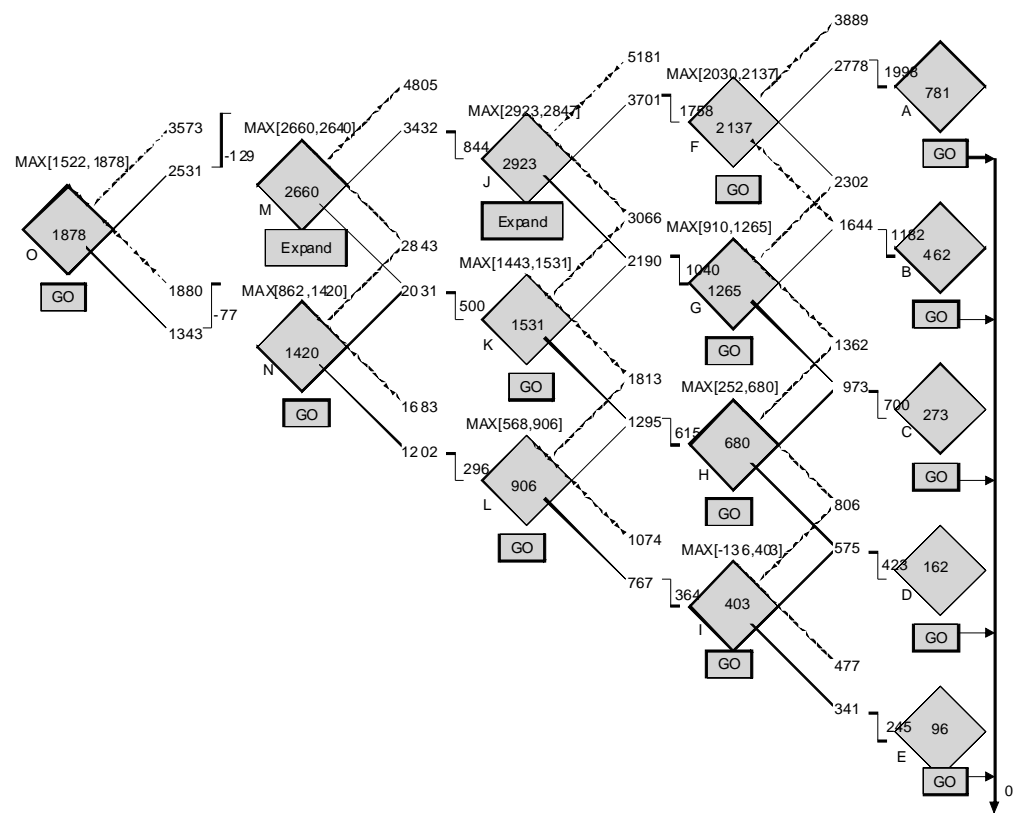

FIGURE 5.- Real Option Solution

The result, namely $\$ 500$, double checks with the expected cash flow of year 2 in exhibit 3.

Figure 4 shows a value tree with the optimal decisions at its end nodes. However, it has not been solved backward in time. Figure 4 is just an intermediate look at the first step in the final solution. Recall that at node $\mathrm{A}$, the value is $\$ 781$, and the decision is "GO", in other words "go ahead" and do not exercise the option to expand. Working one step back into the tree, compare the value of the option if kept alive versus the value of the option if exercised at node $F$ where the up state value is $\$ 2778$ and in the down state it is. \$1644. At node F decide whether to do nothing, i.e., wait, and therefore keep the option alive, or to exercise it at a cost of $\$ 700$.

Figure 5 shows the final solution to the problem, and due to its complexity, it needs the thousand words that do not usually accompany a picture.

Continuing to work backward from end nodes A and B, the root node for this pair is $\mathrm{F}$. The upstate payout is obtained by determining the expected dividend, $71.9 \%$ (see fig. 3) of $\$ 2,778$ i.e., $\$ 1998$, and 
adding it to $\$ 781$. In the most favorable state of nature in year 4 , the value is $\$ 2,778$, without expansion and $1.4(\$ 2,778)=\$ 3,899$ if, at node $\mathrm{F}$, the firm decides to expand. The down state pays off either $\$ 2,302$ if operations have been expanded, or $\$ 1,644$ if not. Next, figure out the value of the firm at node $\mathrm{F}$, assuming no exercise of the expansion option - the "GO" alternative - and compare it with the value of exercising the option at this point - the "Expand" alternative. Then select the higher valued of the two alternatives. Please refer to the appendix for an explanation of how $\$ 2,137$ is calculated as the value of the system at node $\mathrm{F}$. The value of the option is $\$ 2,137$, and if exercised it is $\$ 2,020$, therefore at node $\mathrm{F}$ the decision will be to proceed [GO] without exercising the option. By repeating this procedure and working back from the end nodes to the beginning of the tree, there is the final result that the value of the project with the option to expand is $\$ 1878$ rather than $\$ 1587$ without the option. There is also a decision rule that the project should not be expanded immediately.

The first opportunity to expand occurs at node $\mathrm{M}$, the up state of year 1 . Note that if expansion occurs at this point, the possibility of also expanding at the subsequent shaded node $\mathrm{J}$ is eliminated Given expansion at node "O," the payout would be 1.4(1587) $-700=1522$, which is less than the project value without flexibility. If the option is kept alive; the up state payout is not $\$ 2270$, rather it is the value given expandsion at node $\mathrm{M}$, i.e., $\$ 2660$, less the $\$ 129$ of extra cash invested in the up state at the end of the first year. Therefore, the up state value is $\$ 2660-\$ 129=2531$. The value in the down state is $\$ 1,343$. Refer, once again, to the appendix 1 , for proof that the value of the option, if unexercised, is $\$ 1,832$.

Had the problem been solved differently, by assuming that the project value follows a Geometric Brownian Motion proceeds without dividends, the result would have been very different, and the American option to expand would not have been exercised in the up state of the first year. The more explicit approach that accounts for the pattern of cash flows coming off the project is a crucial determinant of the decision regarding the timing of expansion. Thus, the value of the option to expand is $\$ 1878-\$ 1587=\$ 291$.

\section{A. Basic Assumptions}

Why does the procedure that has just been illustrated provide the right 
answer when closed form solutions with assumed standard stochastic processes cannot? The theoretical underpinnings are three crucial assumptions: Proof that value of properly anticipated cash flows fluctuate randomly (RAP), the marketed asset disclaimer (MAD), and a no arbitrage condition (NOARB).

1. Proof that the value of (the wealth relative of ) properly anticipated (RAP) cash flows fluctuates randomly. ${ }^{4}$ In one of the early mathematical arguments for the efficiency of capital markets, Nobel laureate Paul Samuelson [1965] noted that if the current stock price contained all information about the expected future cash flows, then their pattern over time is already incorporated into today's price. Consequently, the expected rate of change in the wealth of a shareholder is the cost of equity capital. In figure 2, it was demonstrated that the expected shareholder's wealth grows at a constant 10 percent per year, in spite of the fact that cash flows are quite irregular. Deviations from this expected rate of return are driven by deviations from the expected pattern of cash flows and since these deviations are random (for properly anticipated cash flows), deviations in the current stock price are also random. The RAP assumption ensures that the wealth relative and the expected value of the firm follow a recombining binomial stochastic process.

2. Marketed Asset Disclaimer (MAD). To value the option on an underlying risky asset one must find a perfectly correlated twin security that is priced in the market and form a replicating portfolio of $\mathrm{m}$ shares of the twin security and B default free bonds. The end-of-period payouts of this replicating portfolio will exactly equal the payouts of the option, hence its present value is the solution for the value of the option.

The present value of the underlying risky asset without flexibility as taken as the twin security. Naturally, the state contingent cash flows of the project are perfectly correlated with themselves. However, the inflexible underlying risky asset is not traded in the market place. It is necessary to assume that the present value is a good estimate of what the market price of the project would be if it were marketed. This assumption is called the "Marketed Asset Disclaimer" (MAD). Every day companies behave as though the present value of large projects is the same as the price they could get were they to IPO the project or to spin it off. In an important way, they too are making the MAD

4. Read this as "random anticipated prices." 
assumption when they make their capital budgeting decisions using the NPV method.

3. No Arbitrage. The replicating portfolio that is used to price the option at each node of the binomial tree assumes that it is possible to buy or sell positions in the default free bond and the risky inflexible underlying asset. Of course, these positions are not tradable. The real options are priced as if the underlying assets were tradable and as if there were no arbitrage opportunities.

\section{B. Estimating Volatility}

The challenge of estimating volatility is one of the most under-researched and least understood issues in real options. In the example above the up and down movements in the binomial tree were assumed to be $u=1.3$ and $d=1 / 1.3$ respectively. Where might they have come from?

First, they are based on the volatility of the wealth relative (the rate of return assuming reinvestment). The assumption of properly anticipated prices ensures that the expected return is equal to the discount rate for the project without flexibility. Cox, Ross and Rubinstein [ 1979] showed that the standard deviation of this rate of return could be converted into a binomial up movement as follows:

$$
u=e^{\sigma \sqrt{T}}
$$

Sigma is the standard deviation per year of the rate of return on wealth relative of the project (not of its cash flows) and $T$ is the fraction of a year represented by one binomial trial. Usually sigma is estimated in one of two ways. The first uses historical data and Monte Carlo simulation, and the second uses forward-looking estimates.

The present value of the cash flows in our example project was $\$ 1587$. Call this $V_{0}$. Given historical data about the price of the product, and the belief that price is the main driver of uncertainty, it is possible to calculate the historical standard deviation of prices and use it in a Monte Carlo simulation. For example, recalculate the present value 1000 times, obtain a rate of return each time by holding $V_{0}$ constant and estimating

$$
r=\ln \left(V_{l} / V o\right)
$$


where $V_{i}$ is the $P V$ cum dividend, $P V @ t$, at the end of the first period, and In is the natural logarithm. In this way, 1,000 estimates of the rate of return are obtained and from them their standard deviation can be calculated to figure out what number to use for the up movement.

A second, forward-looking approach, asks management to provide an estimate of the 95 percent confidence interval for prices $T$ years in the future.

$$
P \in\left[\text { upper } P_{T} \text {, lower } P_{T}\right]
$$

By assuming a log-normal distribution

$$
P \in[\bar{P} T+2 \sigma \sqrt{T}, \bar{P} T-2 \sigma \sqrt{T}]
$$

The total growth in price over $T$ years will be the sum of the one-year growth rates, $g_{i}$,

$$
R_{T}=\sum_{i} g_{i}
$$

The upper and lower confidence limits for the price will be

$$
\begin{aligned}
& \text { upper } P_{T}=P_{0} e^{\sum g_{i}+2 \sigma \sqrt{T}} \\
& \text { lower } P_{T}=P_{0} e^{\sum g_{i}-2 \sigma \sqrt{T}}
\end{aligned}
$$

and the volatility estimate will be:

$$
\sigma=\frac{\ln \left[\frac{V_{T}^{\text {upper }}}{V_{0}}\right]-\sum_{i=1}^{N} g_{i}}{2 \sqrt{T}}, \quad \sigma=\frac{\sum_{i=1}^{N} g_{i}-\ln \left[\frac{V_{T}^{\text {lower }}}{V_{0}}\right]}{2 \sqrt{T}}
$$

These estimates are, in principle, equal to each other, and can be used in the Monte Carlo estimation of sigma for the wealth relative, as was described earlier in this section.

As long as the decision tree is based on the project's value itself, and not on a driver of uncertainty such as price, quantity, technological change, or input costs, then we can rely on the RAP assumption to argue that the stochastic process that governs the distribution of returns will 
be a random walk, thereby making it unnecessary to model mean reversion (except insofar as it affects the drivers of uncertainty.)

\section{Cases Examples of Real Option Applications}

This section describes five short cases that illustrate the usefulness of real options analysis (ROA) and help differentiate it from Net Present Value (NPV), Decision Tree (DTA), and Scenario analysis (SA). ROA may be perceived as more complicated in terms of its methodology, but it is also more intuitive and gives better answers when the flexibility value is high. When is that? Some projects have deep in-the-money options, that one is virtually certain of exercising. In these situations NPV works fine. Circumstances mitigate the need for flexibility. The opposite case happens when the option is so far out-of-the-money that it is very unlikely to be exercised and has low value - too low to turn a negative NPV positive. Again, NPV might work fine - the project can be rejected. Real options make an enormous difference when the option is close-to-the-money. The NPV of the project may be plus or minus 10-20 percent of the initial capital expense and the additional value of the option may add 50 to 100 percent, or more, to the value of the inflexible project.

Real Options Help Avoid False Mutually Exclusive Alternatives. The first example involves a company that was bidding on the right to develop a government-owned tract of land that contained coal deposits. The winner of the bid for the lease rights could develop it and extract coal starting as long as five years after winning the bid, but if no development was initiated during that time limit, the lease would revert to the government. One of the facts that made the analysis interesting was that the market price per ton of coal was only $\$ 1$ above the extraction cost. A one dollar decrease in the price would wipe out profits and a one dollar increase would double them.

The initial NPV analysis done by the company's analysts used reasonable assumptions about the expected growth in the price per ton of coal, good estimates of extraction costs and other expenses, and discounted the cash flows at a reasonable cost of capital. When the cost of development was subtracted, the net present value of the project was $\$ 52.2$ million.

There had been considerable debate about whether the development 


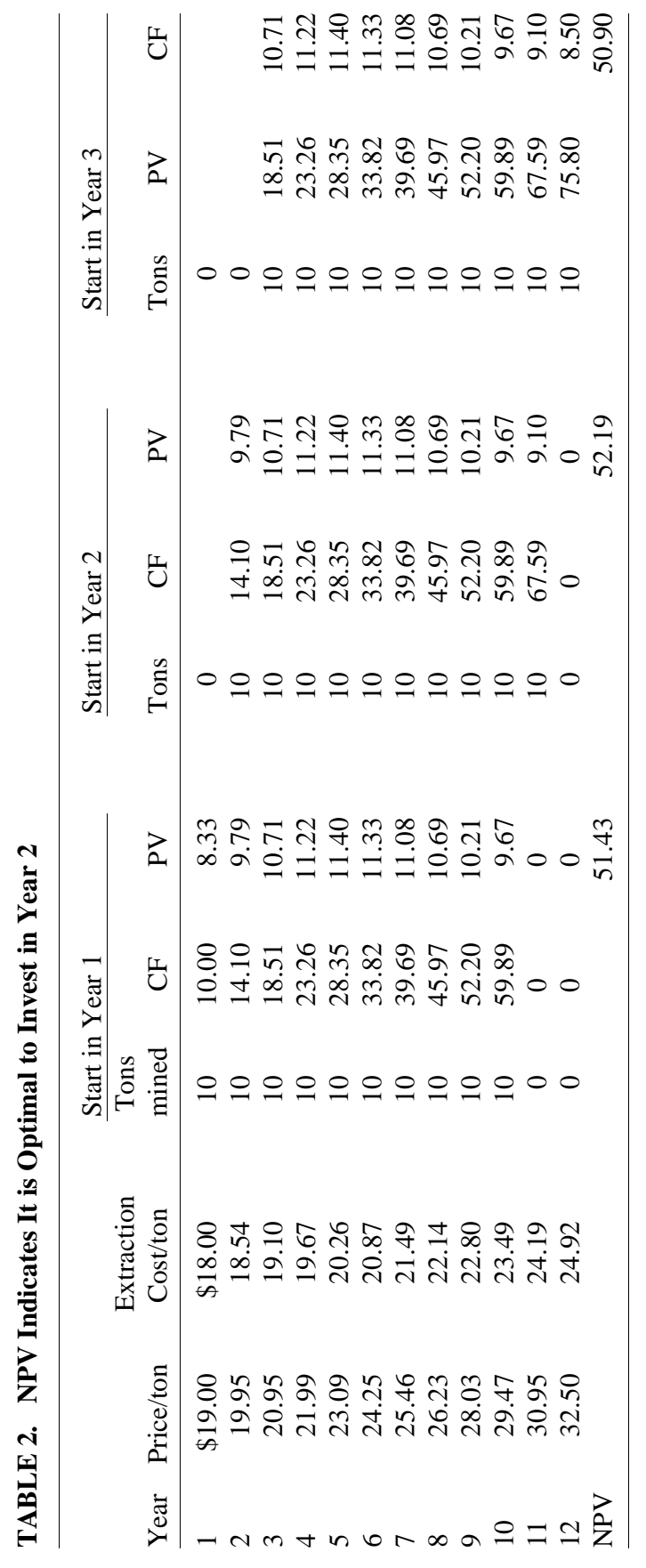




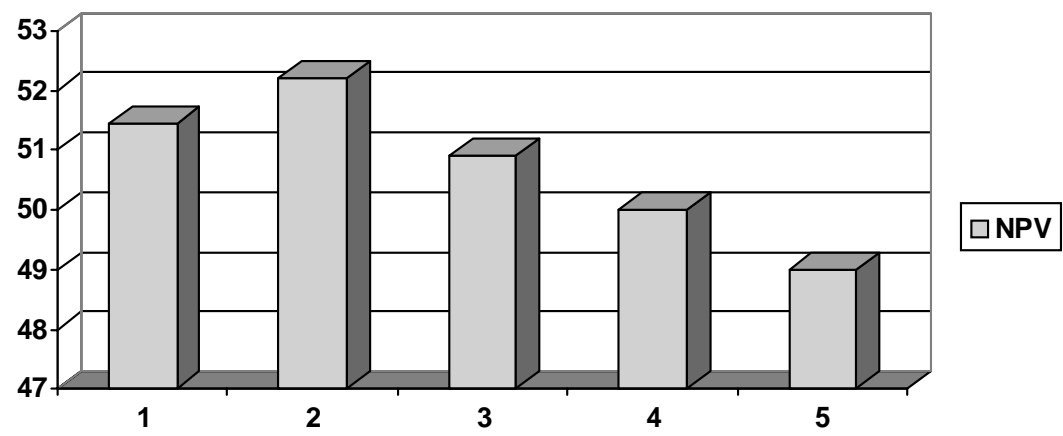

FIGURE 6.- NPVs of 5 Mutually Exclusive Lease Development Scenarios

should begin immediately, after one year, after two years and so on, up to the five year limit - five mutually exclusive NPV estimates. The $\$ 52.2$ million estimate assumed development after year two and was the highest among them.

Table 2 and figure 6 provide a simple numerical example of the value of the project given precommitment to develop in year $\mathrm{N}$. The year 1 price of coal is $\$ 19$ per ton, growing at 5\% per year. The extraction cost is $\$ 18$ per ton and grows at 3\% per year. The reserve of coal is 100 tons and once a development cost of $\$ 53$ million is paid, coal can be mined at the rate of 10 million tons per year. The discount rate is $20 \%$. (We ignore debt and taxes.) The NPV analysis in table 2 has a maximum value of $\$ 52.19$ but assumes that the investment will be made in every state of nature in year 2.

The team decided to investigate the use of real options instead. By working backward in time through the tree they got a single NPV from the real options analysis plus decision rules about what price of coal was necessary to open-the mine. The real options value was greater than the maximum of the mutually exclusive NPV choices, and in this case it turned out to be $\$ 71$ million (without consideration of the value of options to close and then reopen the mine). The company won the lease contract by submitting a bid of slightly less than $\$ 71$ million.

Real Options Can be Used to Segment the Market on Volatility. The chief financial officer of a manufacturer of jet engines wanted to try to value the cancellation feature on operating leases on jet aircraft that the 
company owned. You may ask, "Why would a maker of jet engines actually own aircraft? That is not exactly good for diversification." The reason is that competition to get engines onto the wings of aircraft is fierce due to the fact that, once there, the engines generate a thirty-year stream of spare parts that is more valuable than the engines themselves. Consequently, the manufacturers of jet engines will purchase the airframe for an airline and, then lease it as long as the airline agrees to put the manufacturer's engines onto the wings. Additionally, it is not unusual for the lease to be cancelable (with a minimum fee or even none at all) pre-delivery and up to one year after delivery.

The transaction prices of aircraft bought and sold in the (active) second-hand market were used to estimate the price and volatility in the price of both wide and narrow-body aircraft. It turned out that the value of the cancelable operating lease for narrow-body aircraft was 83 percent of the value of the engines.

When he heard the results, the CFO was astounded. "If the valuation of the cancellation feature is that high, there is nothing I can do, because if I stop offering cancellation, I will loose all of my customers." True, but suppose the market were segmented by customer volatility? The option to cancel will be even higher in value for those airlines that have above average volatility in passenger revenue miles. Airlines with the lowest volatility will rarely cancel their leases. The solution recognized that the demand for the cancellation depended on the volatility of passenger revenue miles. The jet engine manufacturer stopped offering the cancellation feature to those airlines that were in the highest decile when ranked by the volatility of passenger-revenue miles - and lost about half of its customers in this decile. However, soon the market for air travel softened and airlines began to cancel their operating leases but our client suffered a much lower cancellation percentage and saved several hundred million dollars as a result. The lesson learned in this case is not so much the fact that real options can be extraordinarily valuable, but that one can actually segment the market based on the volatility of the underlying risky asset.

Switching Options with Path Dependency. Switching options involve the right, but not the obligation, to shut down and then restart, operation of a business. Examples are peak load power plants that are idle most of the time but are turned on when the hourly price of electricity spikes; the opening and closing of mining operations; and the decision whether or not to exit a seemingly unprofitable business. 


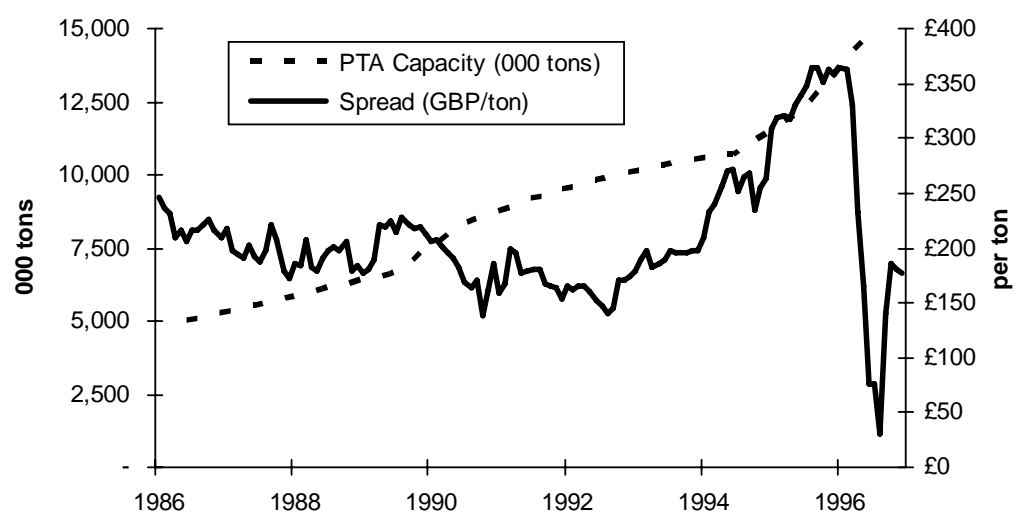

\section{FIGURE 7.- Historical PTA Spread Drives Uncertainty}

Take for example, a heavy oil well that is currently shut down because the market price is $\$ 40$ and it costs $\$ 45$ a barrel to ,extract the oil. Also, the startup costs $\$ 1$ million to pump enough live steam into the reserve to make the oil viscous enough to pump it out of the ground. Normally, one would argue that the well should be opened as soon as the market price exceeds $\$ 45$ per barrel, but this would be premature because, there is roughly a 50-50 probability that the price will drop below $\$ 45$ the next day, and we would have spent $\$ 1$ million to open the well only to close it again. Instead, we should wait to open the well until the spread over $\$ 45$ times the extraction rate (barrels per day) is high enough to cover the opening fixed cost of $\$ 1$ million. If the well is operating and the oil price falls, similar logic applies. The well should be kept open, operating at a loss, until the expected loss equals the cost of shutting down.

The fixed costs of starting up and of shutting down make it more difficult to use a binomial tree to solve the problem, because it will no longer be recombining. Instead of having a binomial tree with $T$ branches after $T$ time periods, a non-recombining binomial tree will have $2_{T}$ branches - a number that soon becomes too large to handle easily.

Another complication of non-recombining trees is that one must use a "backward-forward" algorithm. One must solve each backward movement in the tree two ways - assuming the project is shut down 


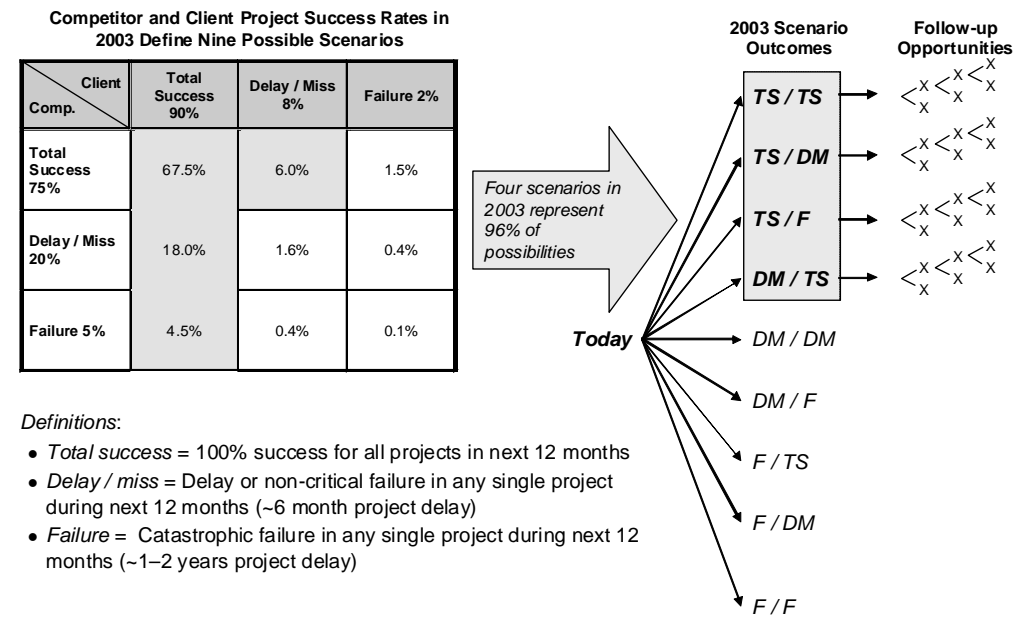

FIGURE 8.- Scenario Analysis

upon entering the state of nature or that it enters the state in a shut-down mode of operation. Only when we have chosen the better of the two values do we know whether the well should have been open or shut upon entering that state, and only then can we move backward one more step in the tree.

Compound Options: Most Common Application. Compound options are options whose exercise depends on the value of other options. Examples cover most large projects and include research and development programs, exploration and development, new product development, and any phased investment. One example of a phased investment is provided by Xylene's Basement case (available from Harvard Business Online). A large chemical company was contemplating an investment in a $\$ 650$ million PTA plant. PTA is the stock chemical compound that is used primarily for polyester clothing and PCV piping. The spread between the output chemical, PTA, and the input chemical, p-xylene is cyclical (mean-reverting), as shown in figure 7. When the spread widens, new capacity is 'constructed and the spread narrows until demand catches up with supply and the spread widens again. At the time of analysis the spread was roughly average, having narrowed recently. The NPV analysis done by the chemical 


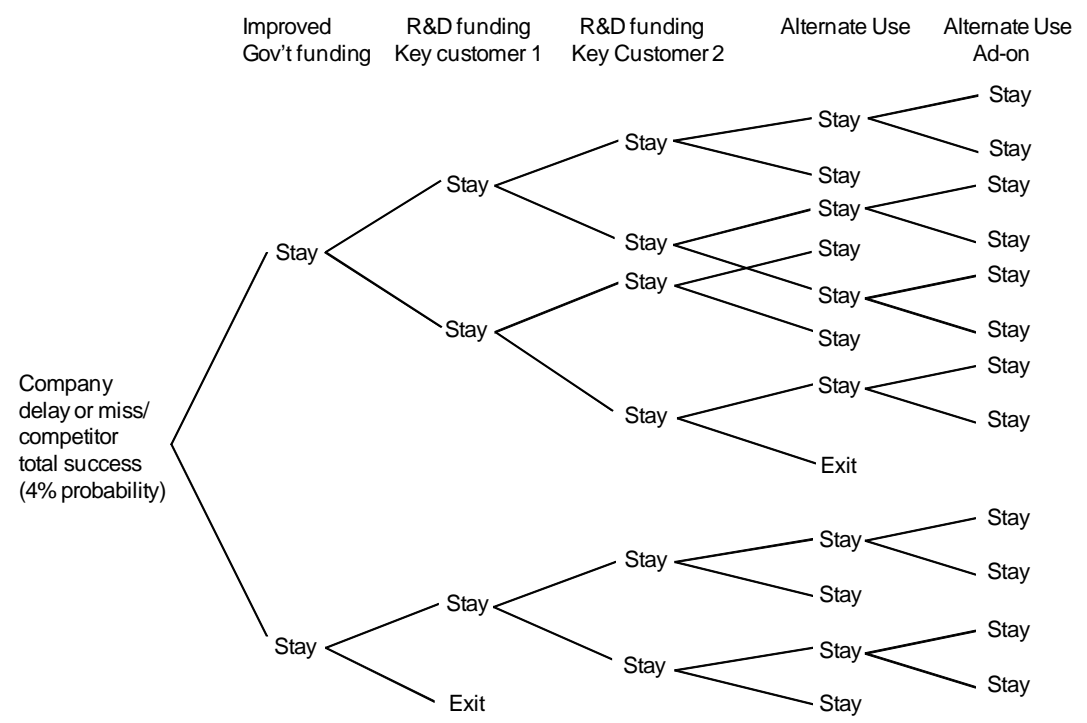

FIGURE 9.- Real Options Analysis Replaces Scenarios

company assumed that the spread would remain at mid-cycle and the result was a value of negative $\$ 72$ million.

But NPV assumed that the three phases of the project, $\$ 50$ million for design of the plant over a 6-month period, \$200 million over a second 6-month period for engineering and pre-construction work, and another $\$ 400$ million over a year to complete construction, would all be completed as scheduled without any options to abandon or defer the second and third phases. When these options were included, the value of the project turned out to be over $\$ 400$ million more than the original estimate.

The chemical company decided to start into the design phase knowing that if the spread narrowed by the end of the first six months the project would be mothballed or completely abandoned. When the spread improved, they went into the second stage, and when it improved again at the end of that phase, they completed construction and were the first to market with new capacity in a widening spread.

Real Options Dominate Scenario Analysis. A company was about to make a board-level decision to exit a major, highly technical line of business that contributed roughly one third of total sales but no profits. 
Demand Matrix (units in thousands, probability in parentheses)

\begin{tabular}{ccrr} 
present & Year 1 & \multicolumn{1}{c}{ Year 2 } & \multicolumn{1}{c}{ Year 3 } \\
0 & $390 *(0.435)$ & $1014 *(0.189)$ & $1977 *(0.082)$ \\
& $231(0.565)$ & $600(0.492)$ & $1170 *(0.321)$ \\
& $355(0.319)$ & $692(0.417)$ \\
& & & $410(0.180)$
\end{tabular}

*capacity will be capped

FIGURE 10.- Capacity Constraints Reduce Expected Supply

Note: Given that demand in the first period can overshoot its expected value by 30 percent or undershoot by $1 / 1.3$, then if a 300 unit plant is built there will be a capacity cap. Similar caps appear in the other periods as well.

When the scenarios, shown in figure 8, were probability weighted, the net present value of the division was roughly negative $\$ 560$ million. But scenario analysis implicitly assumes that each scenario is a mutually exclusive outcome. Real options handles scenarios as a set of contingent outcomes that can be arranged into an event tree such as figure 9, showing the part of the decision tree that would lead to the earliest rational exit decision. Exit would not occur immediately, as the board was contemplating, but a year from now at the earliest, and only if a competitor had total success and the company experienced a delay or partial failure with its product test and if that were not followed by improved government funding nor R\&D funding from a key customer.

When the real options analysis was concluded, the value estimate was considerably higher and optimal decision rules for exiting were delineated to the satisfaction of the board which concluded that the division should not be abandoned.

Modularity Versus Economies of Scale. Consider a firm building manufacturing capacity to meet expected demand for a new high tech laptop computer. Expected sales at a price of $\$ 2,000$ per unit is expected to be 300,000 units the first year, 600,000 the second, and 900,000 the third. Forecasters point out that the standard deviation of their estimates is $26 \%$. The first of two possible manufacturing facilities can produce 900,000 units per year at a cost of $\$ 1,200$ per unit. It costs $\$ 900$ million to build. The other alternative is to build three smaller plants, one a year 
TABLE 3. NPV Analysis of the Small Plant Alternative

\begin{tabular}{lllll}
\hline & Present & Year 1 & Year 2 & Year 3 \\
\cline { 2 - 5 } Expected Output & -- & 261 & 522 & 725 \\
Price per unit & -- & 2 & 2 & 2 \\
Revenue & -- & 522 & 1,044 & 1,450 \\
Variable cost & -- & $(378)$ & $(757)$ & $(1,051)$ \\
Depreciation & -- & $(100)$ & $(200)$ & $(300)$ \\
EBIT & -- & 44 & 87 & 99 \\
Taxes & -- & 17 & 35 & 39 \\
Income & -- & 26 & 52 & 59 \\
Depreciation & -- & 100 & 200 & 300 \\
Salvage value & -- & -- & -- & 300 \\
Capital Expense & $(300)$ & $(300)$ & $(300)$ & - \\
Cash Flow & $(300)$ & $(174)$ & $(48)$ & 659 \\
Discount @ 8\% & 1.000 & 0.926 & 0.857 & 0.794 \\
Present value & $(300)$ & $(161)$ & $(41)$ & 523 \\
Net PV & 21.3 & & & \\
\end{tabular}

Note: Standard Net Present Value Calculations, 3 small plants (thousands). Revised NPVs, 1 large \$38.0, 3 small \$21.3

for three years, each with capacity of 300,000 units and costing $\$ 300$ million. Per unit production costs are $\$ 1,450$.

One has to be a little careful with a standard NPV analysis because capacity utilization limits imply that the ability to supply will be less than demand in some states of nature. Figure 10 shows an event tree for state contingent demand and the ability to meet that demand with the planned construction of three small plants. Notice, for example, that if demand turns out to be 390,000 units in the first year, and there are only 300,000 units of capacity - there will be a shortfall of 90,000 units.

Table 3 shows a standard NPV analysis with the expected output estimates in each year. The NPV of the three-plant alternative is $\$ 21.3$ million. A similar analysis for the single large plant gives $\$ 38$ million. This result is not unexpected because the large plant has a higher operating margin. From a real options perspective, the small plant alternative is modular and providing the option to build more or fewer than three plants in response to the evolution of demand over time. The small plants have greater per unit costs, but they are more flexible. The option to build more factories is path dependent, however. The value of a branch depends on how many plants were open at the beginning of the time period. Consequently, a "backward-forward" algorithm must be used. First, we solve for the value at the up and down branches of a 


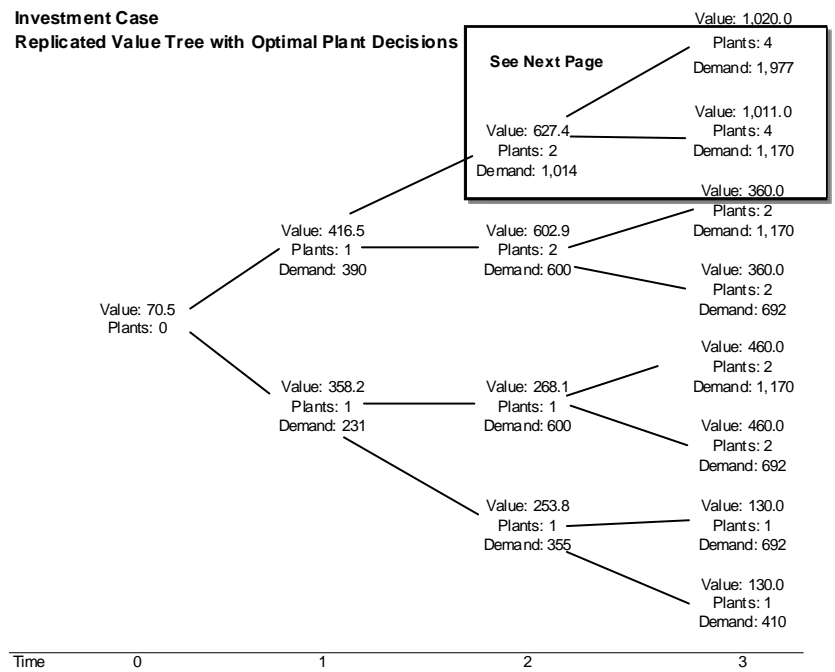

FIGURE 11.- Real Option Valuation of Modular Investments

given node by assuming that $\mathrm{N}$ plants were open at the beginning of the period, then solve again assuming $\mathrm{N}-1$ plants were open, and so forth. Next, use the values at the decision node to determine the optimal number of plants at the beginning of the period.

The final solution is shown in figure 11. It provides the highest-value investment decision results from using the smaller plants that have lower profit margins but are more flexible due to their modularity. The NPV has increased from $\$ 21.3$ million to $\$ 81$ million. Note that one plant is built at first, but if demand turns out to be lower than expected, there will be no additional construction. If demand grows faster than expected, a second plant is constructed in the second year, and if demand increases again then two new plants are constructed, bringing the total to four. Of course, this example has been oversimplified to make a point, namely that flexibility of investment can be more valuable than economies of scale. ${ }^{5}$

5. Graduate schools of engineering are beginning to add real options to their curriculum because it is the only methodology that enables quantification of the tradeoffs between the higher cost of modularity and the benefits of flexibility that it provides. 


\section{Challenges for Using Real Options}

A lot of the progress has been made to solve real options problems that are often more complex and thornier than their financial option counterparts. Black and Scholes [1973] were awarded the Nobel prize for their elegant insight into simple no arbitrage conditions as a solution for a European financial option on a non-dividend-paying stock. The Black-Scholes solution, however, is much too restrictive for use in real options applications. First, most real options are American. Second, they often pay "dividends" in the form of irregular cash flows - the problem that we addressed in section II of this paper. Third, most real options are compound options and involve multiple sources of uncertainty. Finally, many real options are path dependent. Many of these complexities have been overcome, but others remain as challenges. Let me mention a few.

(1) Game theory and real options. Strategists cannot operate in a vacuum. They have to know how other players (e.g. competitors and regulators) will behave when they make a decision such as deferring a phase of research, entering or exiting a market, or a joint venture or acquisition. Although there are solutions for two-person games embedded in a real options setting [see Grenadier (2000), Smit H., and L. Ankum (1993), and Smit and Trigeorgis (2004)] there are, as yet, no comprehensive solutions that combine N-person games with real options.

(2) Switching options with inventory. If a binomial tree is used to model the value of extraction of an exhaustible natural resource such as gold, the amount of gold in the ground decreases when the mine is open, but remains in inventory when the mine is closed. One awkward implication is that as long as the price of gold stays low the mine will remain closed and the inventory of gold in the ground will never be exhausted - hence the binomial tree goes on forever. Only ad hoc assumptions can be used to solve this problem given the current state of knowledge (using binomial trees).

(3) Switching options with multiple modes of operation. What does one do if there are more than two modes of operation - for example high, medium and low speeds, and turned off.?

(4) Problems estimating uncertainty. Referring back to figure 7, is 
the volatility of the PTA spread between 1994 and the end of the graph the same as the volatility before then? Has there been a structured change? Is there mean reversion in volatility as well as price? How much difference does it make in the answer?

(5) Using the wrong uncertainty. The decision is always based on the value of the asset. For example, when deciding whether to develop a gold mine or defer, the economics of the mine is directly relevant. It includes the price of gold, the extraction costs, the cost of opening up and shutting down, and development costs. Consequently, the volatility of returns on gold futures is one of several factors that drives the volatility of return on the mine, but it is not the only one. Therefore, one must estimate the volatility of the mine (and not, for instance the volatility of the equity of the mine).

(6) Changing variance. If the variance changes and we are using a binomial tree, it becomes non-recombining. But what assumptions are reasonable when modeling the variance of the returns on wealth relative over the life of a project? In the numerical example at the beginning of this paper we assumed that since the expected rate of return on wealth relative was constant at 10 percent per year, we could also assume that the variance of said return was constant. Is it? If not how does it change and how do we model it?

(7) Empirical and experimental evidence. Executives often ask how the market can understand and incorporate the value of flexibility into the stock price, when the management team itself does not fully understand real options. We need better empirical evidence that real options explain market prices. There is also a need to design and conduct experimental economics research that provides a clear comparison of NPV with real options.

(8) Need for practical software. In order for real options to be used more in corporate decision-making there is a need for more comprehensive and user friendly software. Currently there are 5 or 6 small companies that are developing real options products. Users need simplicity, e.g. the ability to construct the decision tree that accompanies, and is embedded in real options analysis. They need transparency. When flexibility is assumed away the resulting value should be the NPV of the underlying. Closed-form solutions or first difference methods cannot satisfy this transparency requirement because they are not understandable to executives not trained in the 
math.

The next decade will reveal that real options has almost completely replaced discounted cash flows as the paradigm of choice by top management decision-makers, or that it will suffer a lingering indifference that subjects it to the sidelines. The intuition behind real options is the value of flexibility - a point that almost everyone can agree is fundamental. But the number crunching is perceived by many to be complex and therefore requires standardization, most likely in the form of a versatile, transparent, and user-friendly software routine.

Accepted by: Prof. L. Trigeorgis, Guest Editor, April 2007

Prof. P. Theodossiou, Editor-in-Chief, April 2007

\section{Appendix 1}

Given that an American option has not reached its maturity date, it can either be kept alive or exercised. A rational decision maker will take the alternative that has the greater value. At node $\mathrm{F}$ in figure 5 this may be expressed as

$$
\begin{gathered}
M A X[\text { value if exercised, market value }] \\
=\operatorname{MAX}\left[1.4 V_{3}-300, C_{3, F}\right]
\end{gathered}
$$

We know that the value of the underlying risky asset at node $\mathrm{F}$ is $\$ 1943$, therefore, if exercised, the value of the choice to expand at node $\mathrm{F}$ is

$$
1.4 V_{3}-700=1.4(1943)-700=2020
$$

To solve for the value of the American call, $C_{3, F}$, we can form a replicating portfolio, consisting of $\mathrm{m}$ shares of the project without the flexibility to expand, and B default-free bonds that pay rate of interest, $r$. This portfolio is constructed from two assets whose value we know at the beginning of each time period, and it will have exactly the same payouts as the option that we are trying to value. Since the payouts on the replicating portfolio are perfectly correlated with the expansion option, the value of the replicating portfolio must equal the value of the option in order to prevent arbitrage. This no arbitrage condition is the main difference between real options and decision tree analysis. Let's see how it works. 
We create two equations, each describing the payout of our replicating portfolio in a different state of nature. For the up state, at node $\mathrm{F}$, we have

$$
\begin{gathered}
m u V+B(1+r)=2778 \\
m(1.3)(1943)+B(1.05)=2778
\end{gathered}
$$

Note that $u V=2778$ is the up state payout if we do not exercise the option

\section{Appendix 2}

To calculate the value at node $\mathrm{O}$, we use the same logic as before. The choice is

$$
\begin{gathered}
\operatorname{MAX}[\text { value if exercised, market value }] \\
=\operatorname{MAX}\left[1.4 V_{o}-700, C_{0,0}\right]
\end{gathered}
$$

At time $=0$ the value of the asset is $V_{o}=\$ 1583$, therefore if the expansion option is exercised, the value is

$$
1.4(1587)-700=1522
$$

To determine the value of the option unexercised, we again form a replicating portfolio that pays $\$ 2531$ in the up state and \$1343 in the down state

$$
\begin{gathered}
m(1.3)(1587)+(1.05) B=2531 \\
m(1 / 1.3)(1587)+(1.05) B=1343
\end{gathered}
$$

Solving for $m$ and $B$, we have

$$
m=\frac{2531-1343}{1.3(1587)-0.77(1581)}=\frac{1188}{842}=1.41
$$




$$
B=\frac{2531-1.4(1.3)(1587)}{1.05}=-360
$$

Finally, the present value of the option to expand is

$$
\begin{aligned}
C_{o, o} & =m V_{o}+B \\
& =1.4(1587),-360 \\
& =1878
\end{aligned}
$$

Since this is greater than the value if exercised, we keep the option open

$$
\operatorname{MAX}[1522,1878]=1878
$$

For the down state we have

$$
m d V+B(1+r)=1644 m(1 / 1.3)(1943)+B(1.05)=1644
$$

Subtracting the second equation from the first, we can solve form

$$
m=[2778-1644] /[2516-1495]=1.10
$$

and by substituting $m=1.1$ into the first equation we can solve for $B$ as

$$
B=[2778-1.1(1.3)(1943)] / 1.05=0
$$

The beginning-of-period value of the option is the same as the value of this replicating portfolio. It is composed of 1.1 shares of the underlying asset $(V=1943)$ and zero bonds:

$$
m V+B=1.1(1943)-0=2137
$$

\section{References}

Copeland, T. E., and Antikarov, V. 2001. Real Options: A Practitioner's Guide. 
Texere.

Copeland, T. E. 2002. "Xylene's Basement". Harvard Business School, Case \#9-202-097, Autumn.

Cox, J.; Ross, S.; and Rubinstein, M. 1979. "Option Pricing: A Simplified Approach," Journal of Financial Economics, September, 229-263.

Grenadier, S. (ed.) 2000. Game Choices: The Intersection of Real Options and Game Theory, Risk Books, 2000.

Black, F., and Scholes M. 1973. "The Pricing of Options and Corporate Liabilities," Journal of Political Economy, May-June, 637-654.

Samuelson, P. 1965. "Proof that Properly Anticipated Prices Fluctuate Randomly," Industrial Management Review, 1965, 41-49.

Smit, H., and Ankum, L. 1993. "A Real-options and Game-theoretic Approach to Corporate Investment Strategy Under Competition", Financial Management, Vol. 22, 99-108.

Smit, H., and Trigeorgis L. 2004, Strategic Investment: Real Options and Games, Princeton University Press, Princeton, NJ. 